\title{
Characterization of Thiothrix nivea
}

\author{
JOHN M. LARKIN* AND DEAN L. SHINABARGER \\ Department of Microbiology, Louisiana State University, Baton Rouge, Louisiana 70803
}

\begin{abstract}
Two strains of Thiothrix nivea were examined to determine their morphological and physiological features. Microculture studies revealed the production of gliding gonidia and possible mechanisms for rosette formation. The strains were able to use only 4 of 41 carbon sources tested, but only if sulfide or thiosulfate was present. Physiologically, Thiothrix may be an obligate mixotroph. The guanineplus-cytosine content of the deoxyribonucleic acid was $52 \mathrm{~mol} \%$. Our strains fit the description of $T$. nivea, and strain JP2 (= ATCC 31500) was designated as the neotype strain.
\end{abstract}

Thiothrix was first described by Winogradsky in 1888 (23), but little is known about the biology of this organism because of a lack of pure cultures. The presence of a sheath on Thiothrix has been verified $(1,3,9)$, and the typical rosettes are often seen in sulfide-containing waters. The production of gliding gonidia as reported by Winogradsky (23) has not been adequately verified, and features of the physiology of Thiothrix have not been examined.

The first pure cultures of Thiothrix were obtained recently (9) and were used in this study to (i) verify or refute the properties described by Winogradsky (23), (ii) determine the physiological features of Thiothrix, and (iii) provide an adequate taxonomic description of the organism.

\section{MATERIALS AND METHODS}

Cultures and media. Thiothrix nivea strains JP1 and JP2 were isolated from sulfide-containing well water in John Pennycamp State Park in Key Largo, Fla., by techniques described previously (9). MY (9) and MP (20) media containing either $0.03 \%$ sodium sulfide or $0.03 \%$ sodium thiosulfate were used routinely as solid media $(1.5 \%$ agar) or in tubes containing agar butts with liquid overlays (biphasic). Incubation was at room temperature (about $22^{\circ} \mathrm{C}$ ) unless stated otherwise.

Microculture studies. The life cycle of $T$. nivea strain JP2 was examined in microculture. A small amount of melted MP agar was placed into a Whipple counting chamber, inoculated with 1 drop of a 72 -h culture, and covered with a cover slip. Rosettes, filaments, and single cells were observed and photographed at intervals for up to $36 \mathrm{~h}$.

Morphological features. A Gillet and Sibert phasecontrast microscope fitted with a filar micrometer and a Nikon AFM camera was used to examine and record the morphological features of the strains. Sudan black $B$ was used to detect poly- $\beta$-hydroxybutyrate.

Growth studies. The ability of each strain to grow at different temperatures was examined by inoculating duplicate tubes of biphasic MY medium and incubating these tubes for up to 2 weeks at the desired temperature. The ability of each strain to grow anaerobically was tested in $125-\mathrm{ml}$ serum bottles containing $20 \mathrm{ml}$ of MY broth supplemented with either sulfide or thiosulfate. The medium was boiled for $5 \mathrm{~min}$, flushed with oxygen-free nitrogen, capped with a butyl rubber stopper, autoclaved, and inoculated with a syringe through the stopper.

Utilization of sole carbon sources. Carbon sources were added individually to MP medium lacking acetate to give concentrations of $0.05 \%$, and these preparations were autoclaved. Acid-cleaned glassware was used in all steps. Duplicate sets of media were made. One set contained $0.03 \%$ sodium sulfide, and the other set contained $0.03 \%$ sodium thiosulfate. To be recorded as positive, visible turbidity and tufts of growth had to appear through three successive transfers with a loop.

Utilization of sole nitrogen sources and reduction of nitrate. The ability of each strain to utilize nitrate, nitrite, or ammonia as a sole nitrogen source was examined in screw-capped tubes containing MP broth supplemented with $0.05 \% \mathrm{KNO}_{3}, 0.02 \% \mathrm{NaNO}_{2}$, or $0.02 \% \mathrm{NH}_{4} \mathrm{Cl}$ as the sole nitrogen source. All tubes were incubated for 2 weeks. Nitrate reduction (to nitrite) in the medium containing $\mathrm{KNO}_{3}$ was examined by adding 10 drops of sulfanilic acid and 10 drops of alpha-naphtholamine to 5-day-old cultures.

Utilization of sole sulfur sources. The ability of each strain to utilize elemental sulfur, thiosulfate, sulfite, 2 mercaptoethanol, tetrathionate, sulfate, or sulfide as a sole sulfur source was tested by adding each sulfur source at a concentration of $0.03 \%$ to MP medium. The sulfate salts of the basal medium were replaced by chloride salts.

Production of specific enzymes and hydrolysis of macromolecules. The ability of each strain to produce catalase was tested by scraping 1-week-old growth from an agar surface, suspending it in $3 \%$ hydrogen peroxide, and looking for bubbles immediately and after $5 \mathrm{~min}$. The capillary tube test (4) was also used. Cytochrome oxidase was assayed by scraping growth from an agar surface and smearing it onto filter paper to which 1 drop of $1.0 \% N, N, N^{\prime}, N^{\prime}$-tetramethyl-pphenylenediamine had been added. The rapid appearance of a purple color was considered to be positive (6). The hydrolysis of macromolecules was assayed on four different solid media for each macromolecule that 
was tested. Gelatin $(0.4 \%)$ and starch $(4.0 \%)$ were added to (i) MP medium, (ii) MP medium without a reduced sulfur source, (iii) MP medium without acetate, and (iv) basal salts (20). For casein hydrolysis the above media were made double strength and mixed with an equal amount of sterile nonfat skim milk. Plates were inoculated in duplicate and incubated for 14 days.

DNA extraction and purifications. The strains were grown in 8-liter batch cultures of MY broth with constant agitation, and cells were harvested after $72 \mathrm{~h}$ by centrifugation. Extraction and purification of deoxyribonucleic acid (DNA) were accomplished by the method of Marmur (12), with the following modifications: (i) cells were washed once with $0.25 \mathrm{M}$ ethylenediaminetetraacetic acid and resuspended in $30 \mathrm{ml}$ of $0.25 \mathrm{M}$ ethylenediaminetetracetic acid; (ii) $10 \mathrm{mg}$ of pronase (grade B; Calbiochem, Los Angeles, Calif.) and $10 \mathrm{ml}$ of a $25 \%$ sodium dodecyl sulfate solution were added to the cell suspension, which was then incubated overnight at $60^{\circ} \mathrm{C}$ to achieve suitable lysis; and (iii) cold ethanol was used in all nucleic acid precipitations. Purified DNA was dissolved in $0.1 \times$ standard saline citrate (SSC; $1 \times \mathrm{SSC}$ is $0.15 \mathrm{M} \mathrm{NaCl}$ plus $0.015 \mathrm{M}$ sodium citrate) and analyzed.

Determination of DNA base composition. The guanine-plus-cytosine content of the purified DNA was calculated from the melting point profile obtained with a Gilford model 2400 spectrophotometer equipped with a model 2527 thermoprogrammer, using the formula of Mandel et al. (11). Escherichia coli type VII DNA (Sigma Chemical Co., St. Louis, Mo.) was used as a control.

Electron microscopy. Fixation, sectioning. and staining of Thiothrix were carried out as previously described for Beggiatoa (20). For fixation we used a modified Ryter-Kellenberger technique, and thin sections were stained with uranyl acetate (21) and then lead citrate (16).

\section{RESULTS}

Pure cultures of Thiothrix in MP or MY broth consisted of individual cells, filaments of varying lengths, and rosettes (Fig. 1). The filaments were enclosed in a sheath.

The filament width of the two strains varied from about 1 to $1.5 \mu \mathrm{m}$ when the organisms were grown on MY medium. Both strains were gram negative and produced poly- $\beta$-hydroxybutyrate. Sulfur granules were deposited internally when the strains were grown with either sulfide or thiosulfate, but not when they were grown with the other sulfur-containing compounds tested.

Colonies on either MP or MY agar were thin and spreading with rough edges due to outgrowth of individual filaments (Fig. 2).

In thin sections (Fig. 3) the sheath appeared to consist of several layers, which could separate from each other. The cell wall appeared to be typically gram negative. Both poly- $\beta$-hydroxybutyrate and sulfur were present in the cells, with the former located near the center. The sulfur granules were located near the periphery and were enclosed within invaginations of the cytoplasmic membrane (Fig. 4), thus making them external to the cytoplasm, as in Beggiatoa $(10,19)$.

In microculture, cells that had been deposited singly glided at a rate of about 1 to $2 \mu \mathrm{m} / \mathrm{min}$ (Fig. 5), which is equivalent to the lower rate of movement recorded for some myxobacteria (7). We did not observe rosettes produced from aggregation of these gliding gonidial cells; the lack of rosette formation under these conditions

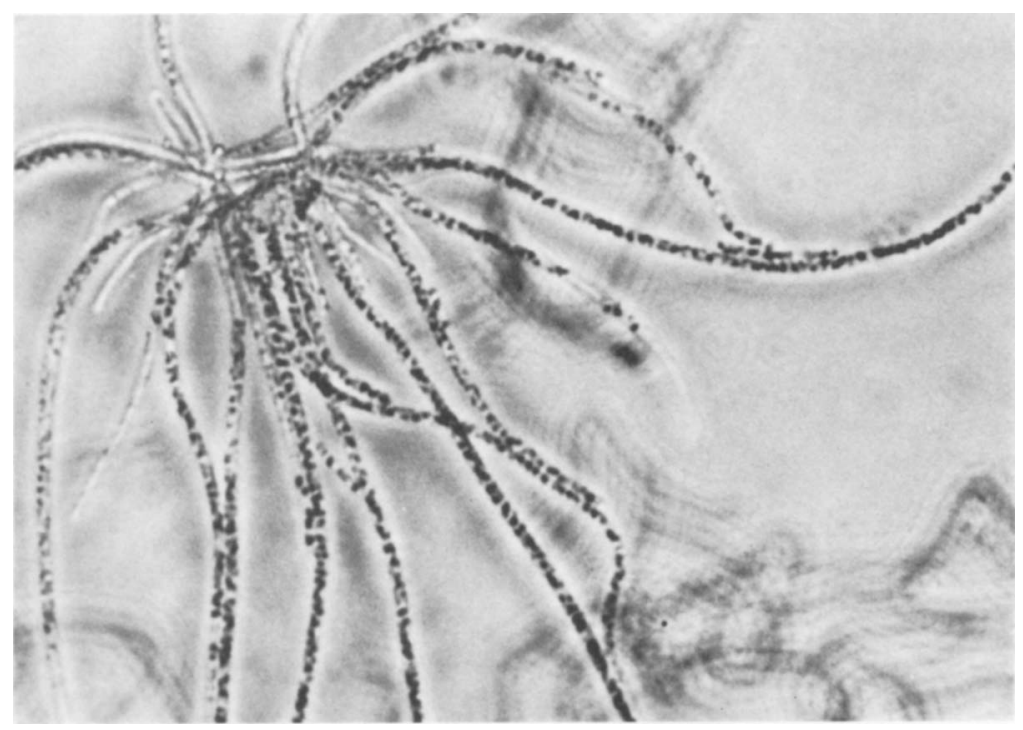

FIG. 1. Rosette of T. nivea strain JP2 grown in MP broth and transferred to an agar-covered slide for photography. 


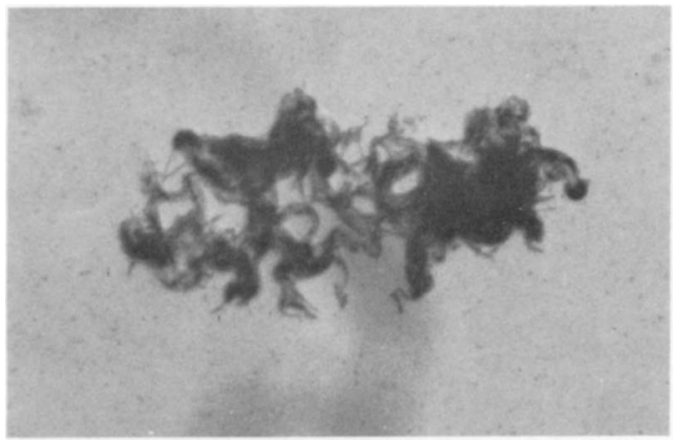

FIG. 2. Typical colonies of $T$. nivea strain JP2 growing on MY agar. Photographed in transmitted light.

may have been because the number of gonidia was too low (5) or because the distances between the gonidia were too great (5). Aggregation of gliding cells is the best explanation for the presence of rosettes which contain only single cells or short filaments $(5,9)$ (Fig. 6, step C). Frequently, several cells in succession were released from the end of a filament; these cells remained in place, and the filament eventually grew past them (Fig. 6, sequence A). This process may be the mechanism by which the rosettes attached to filaments are produced. Rosettes are frequently attached to filaments in nature (9). The ability of the gonidia to remain attached where they are produced may be important in preventing them from washing downstream into an unsuitable environment. Electron micrographs (manuscript in preparation) showed that single cells had a tuft of fimbriae at one end and that the fimbriated end was always the end that was attached to another cell. No flagella were found.

Both strains grew best at 25 to $30^{\circ} \mathrm{C}$, and no growth occurred at 6 or $34^{\circ} \mathrm{C}$. Growth was slow at $20^{\circ} \mathrm{C}$. No growth occurred under anaerobic conditions.

Both strains produced cytochrome oxidase but not catalase. Neither strain hydrolyzed starch, gelatin, or casein under any of the four conditions tested, and growth in the hydrolysis media occurred only when acetate and thiosulfate were present.

Acetate, malate, pyruvate, and oxalacetate were utilized as sole carbon sources by both strains, but only if sulfide or thiosulfate was present. The carbon sources which failed to support growth through at least three successive transfers were formate, citrate, cis-aconitate, succinate, fumarate, phosphoenolpyruvate, carbonate, glyoxylate, methylamine, propionate, lactate, glucose, lactose, fructose, sucrose, maltose, ribose, mannose, arabinose, cellobiose, rhamnose, raffinose, sorbose, melibiose, xylose, ethanol, methanol, propanol, glycerol, erythritol, asparagine, cysteine, methionine, serine, glutamate, and aspartate. Ammonia and nitrate were used as sole nitrogen sources. $\mathrm{Ni}$ trate was reduced to nitrite. Nitrite did not

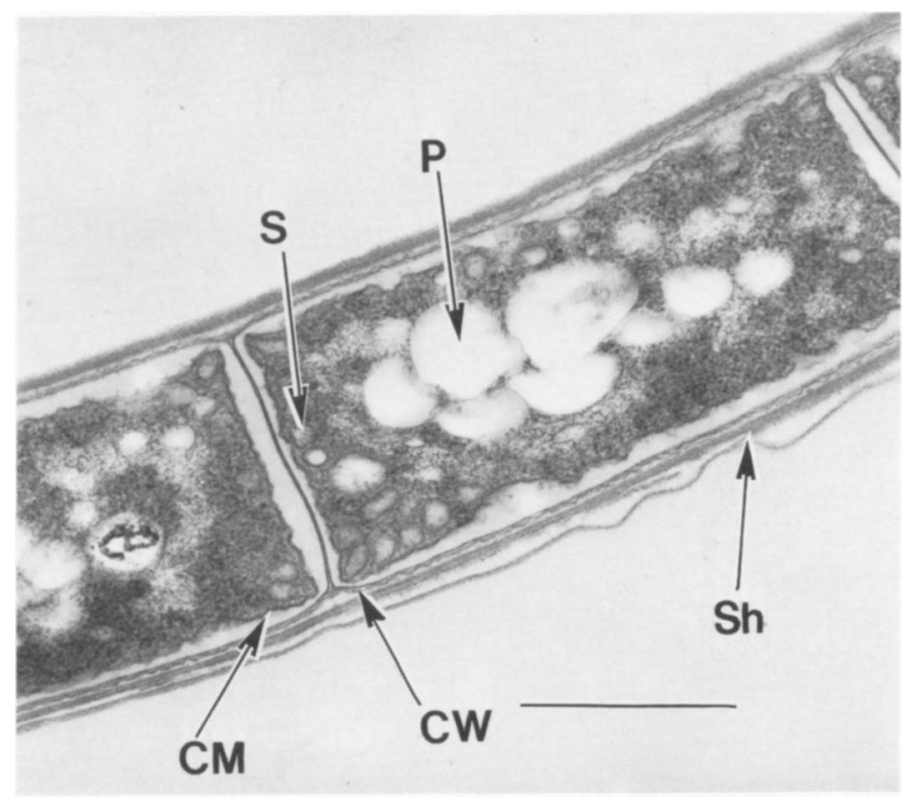

FIG. 3. Thin section of $T$. nivea strain JP2. Sh, Sheath; CW, cell wall; CM, cytoplasmic membrane; S, sulfur granule; $\mathrm{P}$, poly- $\beta$-hydroxybutyrate. $\mathrm{Bar}=1 \mu \mathrm{m}$. 


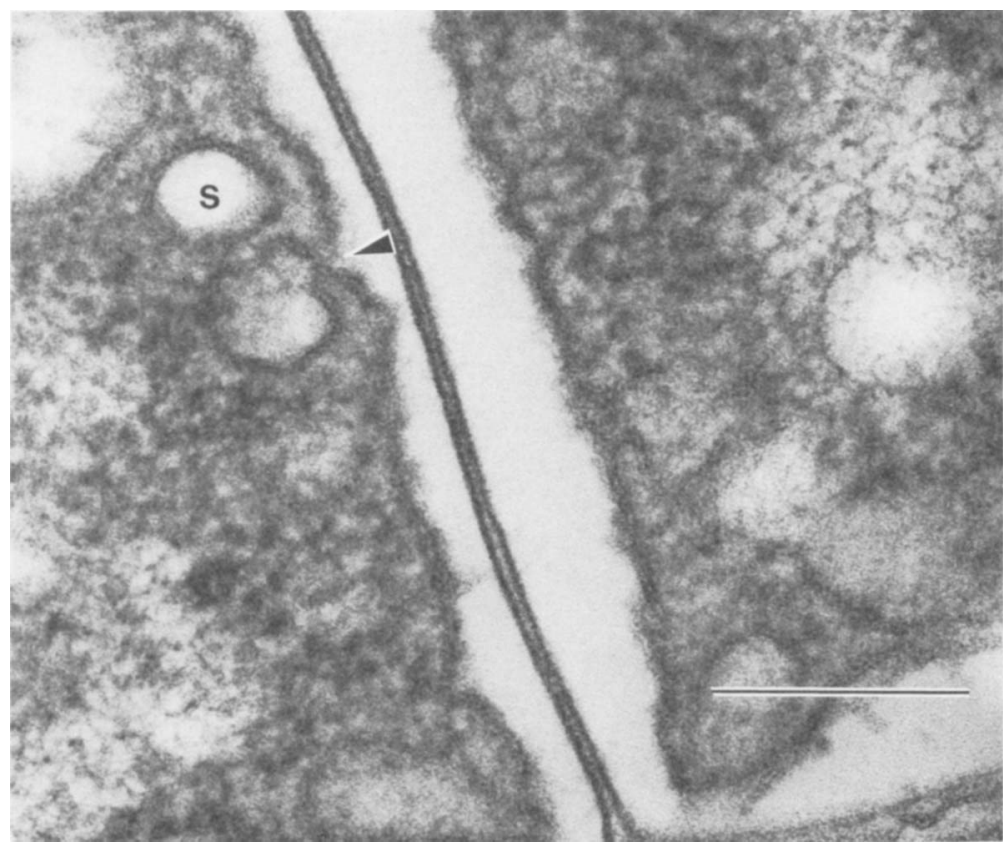

FIG. 4. Enlargement of the septal region of the cell shown in Fig. 3. A typical invagination (arrowhead) enclosing a sulfur granule and a sulfur granule $(S)$ are present. Bar $=250 \mathrm{~nm}$.
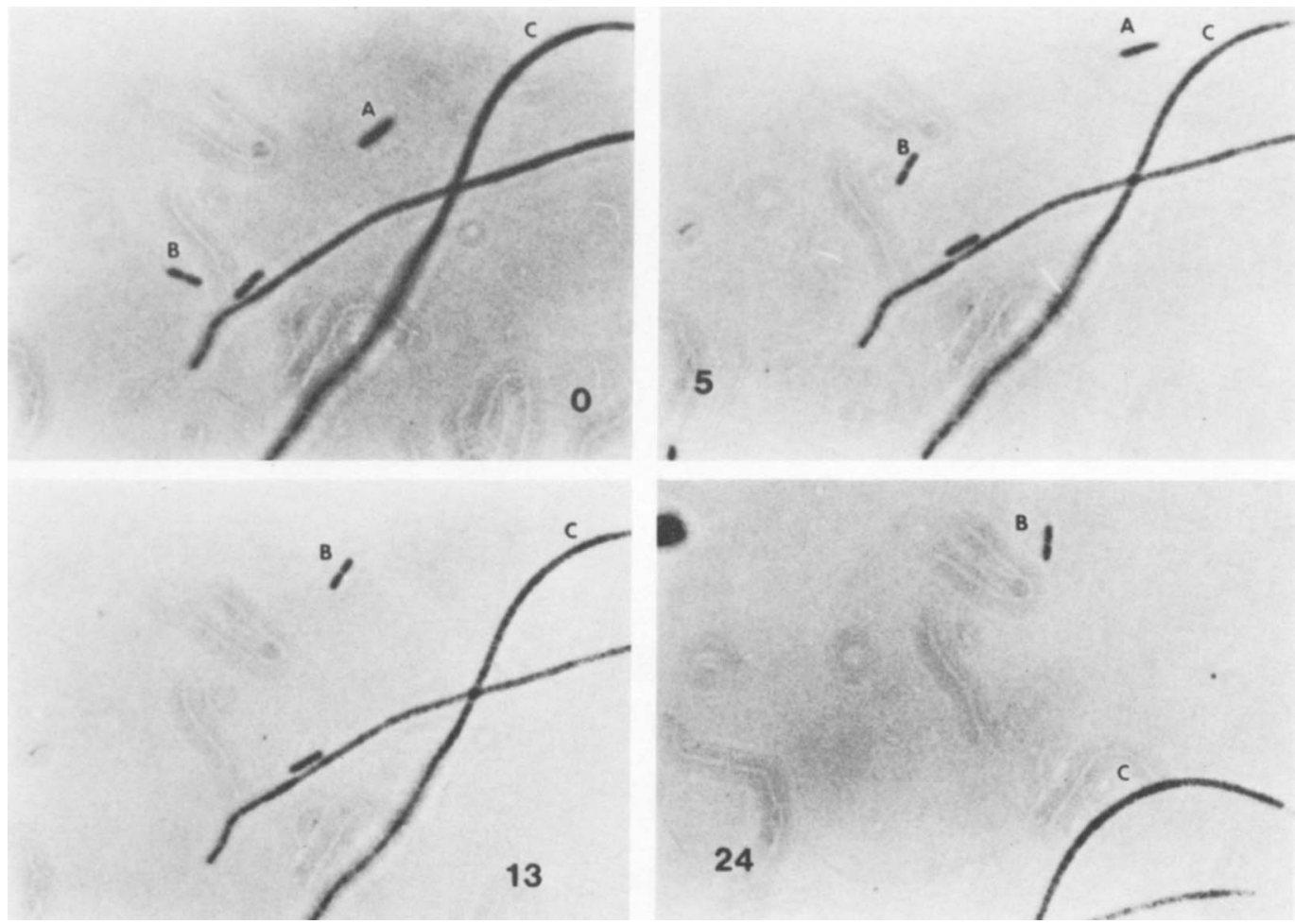

FIG. 5. Gliding of $T$. nivea strain JP2 in microculture. Cells A and B moved in relation to filament $C$ in photographs taken at $0,5,13$, and $24 \mathrm{~min}$. The slide was repositioned to include the gonidium and filament in the 24-min photograph. 


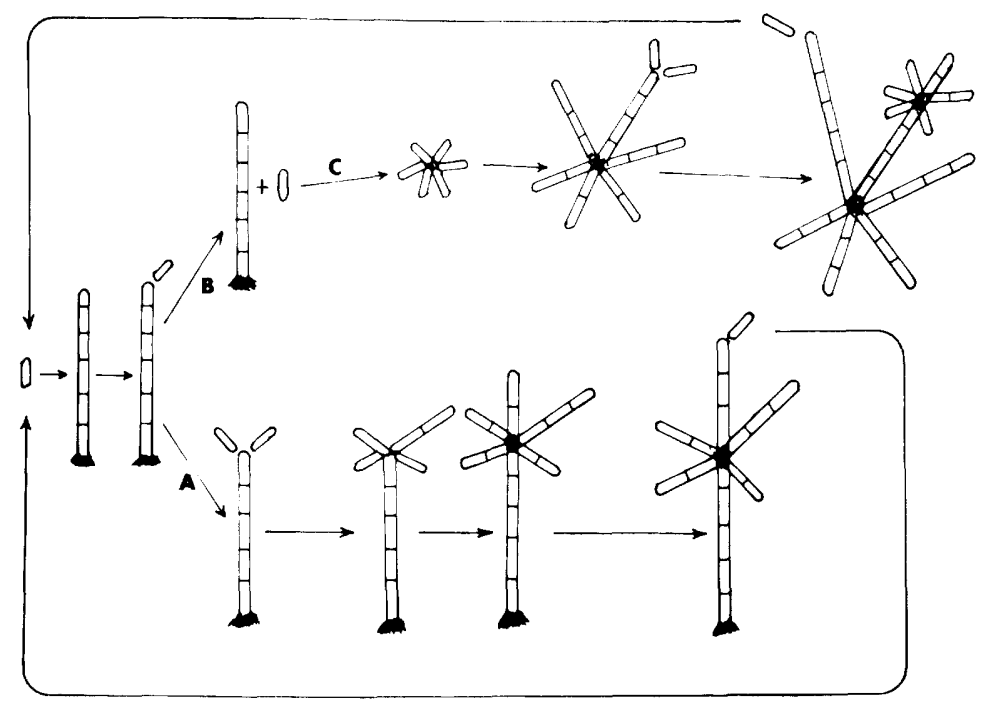

FIG. 6. Proposed life cycle of $T$. nivea, based on micro- and macroculture studies.

support growth, and no growth occurred in nitrogen-free media. Sulfide and thiosulfate served as sole sources of reduced sulfur, but sulfite, sulfate, tetrathionate, and 2-mercaptoethanol did not support growth.

The guanine-plus-cytosine content of the DNA of both strains was $52 \mathrm{~mol} \%$.

\section{DISCUSSION}

T. nivea was originally named Beggiatoa nivea (14), but Winogradsky (23) placed this organism into his newly created genus Thiothrix as the type species. No pure cultures were obtained, and his description was based on observations of collected samples. Winogradsky stated that $T$. nivea (i) deposited sulfur internally in the presence of sulfide, (ii) attached to objects by means of a sticky substance at one end of the filament, and (iii) produced a sheath, gliding gonidia, and rosettes. The presence of sulfur granules has been verified $(1,3,9)$, as have the ability to attach to objects $(1,9,13)$ and the ability to produce rosettes $(1,9)$. The presence of a sheath has been verified several times $(1,3$, 9); however, the existence of a sheath was ignored in Bergey's Manual of Determinative Bacteriology, 8th ed. (2), and in a recent review Reichenbach stated that a sheath does not exist in this organism (15). The production of gliding gonidia was verified by Wille (22), but his observation was discounted by Harold and Stanier (5). We have verified the production of gliding gonidia. The two strains of Thiothrix used in our work have all of the features described previously for Thiothrix.

Winogradsky (23) postulated that $T$. nivea is autotrophic, obtaining carbon from $\mathrm{CO}_{2}$ and energy from the oxidation of sulfide. However, he was unable to prove this hypothesis because of a lack of pure cultures and the possible presence of organic material in his preparations. Our strains of $T$. nivea did not grow in the absence of organic material or in the absence of either sulfide or thiosulfate. Either of these reduced sulfur compounds (with acetate, malate, pyruvate, or oxalacetate as a carbon source) supported growth of the two strains, and sulfur was deposited internally. Strohl and Schmidt (in W. R. Strohl and O. H. Tuovinen, ed., Microbial Chemoautotrophy, in press) have shown that strains JP1 and JP2 fix $\mathrm{CO}_{2}$ via phosphoenolpyruvate carboxylase and the malic enzyme. These data suggest that our $T$. nivea strains are obligate mixotrophs which obtain energy from the oxidation of sulfide or thiosulfate and carbon from $\mathrm{CO}_{2}$ and organic compounds. We are doing additional work to examine this point further. If autotrophic strains of Thiothrix exist, they have not been isolated yet.

A total of 11 species of Thiothrix have been described $(2,17)$. These organisms are differentiated solely on the basis of the diameters of their filaments and by the environments in which they are found. Lackey et al. (8) believe that $T$. nive $a$ and Thiothrix tenuis are the only legitimate species. Only $T$. nivea is recognized by Bergey's Manual (2) and is on the Approved Lists of Bacterial Names (18). Our isolates fit the description of $T$. nivea of Winogradsky (23), and we consider them to be this species. Strain JP2 is designated as the neotype strain. Strains JP1 and JP2 have been deposited with the American 
Type Culture Collection as strains ATCC 35099 and ATCC 35100, respectively.

\section{ACKNOWLEDGMENT}

We thank Rod Nelson for preparing the electron micrographs.

\section{LITERATURE CITED}

1. Bland, J. A., and J. T. Staley. 1978. Observations on the biology of Thiothrix. Arch. Microbiol. 117:79-87.

2. Brock, T. D. 1974. Genus Thiothrix, p. 119. In R. E. Buchanan and N. E. Gibbons (ed.), Bergey's manual of determinative bacteriology, 8th ed. The Williams \& Wilkins Co.. Baltimore.

3. Drawert, H., and I. Metzner-Kuster. 1958. Fluorescenzund elektron-mikroscopisch Untersuchungen an Beggiotoa alba und Thiothrix nivea. Arch. Mikrobiol. 31:422434

4. Fung, D. Y., and D. T. Petrishko. 1973. Capillary tube catalase test. Appl. Microbiol. 26:631-632.

5. Harold, R., and R. Y. Stanier. 1955. The genera Leucothrix and Thiothrix. Bacteriol. Rev. 19:49-64.

6. Jurtshuk, P., Jr., and D. N. McQuinty. 1976. Survey of oxidase-positive and -negative bacteria using a quantitative Kovacs oxidase test. Int. J. Syst. Bacteriol. 26:127135 .

7. Kaiser, D., and C. Manoil. 1979. Myxobacteria: cell interactions, genetics, and development. Annu. Rev. Microbiol. 33:595-639.

8. Lackey, J. B., W. W. Lackey, and G. B. Morgan. 1965. Taxonomy and ecology of the sulfur bacteria. Eng. Prog. Univ. Fla. Bull. Ser. 119 19:3-23.

9. Larkin, J. M. 1980. Isolation of Thiothrix in pure culture and observation of a filamentous epiphyte on Thiothrix. Curr. Microbiol. 4:155-158.

10. Maier, S., and R. G. E. Murray. 1965. The fine structure of Thioploca ingrica and a comparison with Beggiatoa.
Can. J. Microbiol. 11:645-655.

11. Mandel, M., L. Igambi, J. Bergendahl, M. L. Dodson, and E. Scheltger. 1970. Correlation of melting temperature and cesium chloride buoyant density of bacterial deoxyribonucleic acid. J. Bacteriol. 101:333-338.

12. Marmur, J. 1961. A procedure for the isolation of deoxyribonucleic acid from micro-organisms. J. Mol. Biol. 3:208-218

13. Morita, R. Y., and S. D. Burton. 1965. Filamentous appendages of Thiothrix. Z. Allg. Mikrobiol. 5:177-179.

14. Rabenhorst, L. 1865 . Flora europa algarum aquae dulcis et submarinae, sect. II. E. Kummer, Leipzig.

15. Reichenbach, H. 1981. Taxonomy of the gliding bacteria Annu. Rev. Microbiol. 35:339-364.

16. Reynolds, E. S. 1963 . The use of lead citrate at high $\mathrm{pH}$ as an opaque stain in electron microscopy. J. Cell Biol. 17:208-212.

17. Rodina, A. G. 1963. Sulfur bacteria in the detritus of lakes in the Lagoda district. Microbiology (USSR) 35:575-580. (English translation.)

18. Skerman, V. B. D., V. McGowan, and P. H. A. Sneath (ed.). 1980. Approved lists of bacterial names. Int. J. Syst. Bacteriol. 30:225-420.

19. Strohl, W. R., K. S. Howard, and J. M. Larkin. 1982 Ultrastructure of Beggiotoa alba strain B15LD. J. Gen. Microbiol. 128:73-84

20. Strohl, W. R., and J. M. Larkin. 1978. Enumeration, isolation, and characterization of Beggiatoa from freshwater sediments. Appl. Environ. Microbiol. 36:755-770.

21. Watson, M. L. 1958. Staining of tissue sections for electron microscopy with heavy metals. II. Applications of solutions containing lead and barium. J. Biochem. Biophys. Cytol. 4:475-479.

22. Wille, N. 1902. Ueber Gasvakuolen bei einer Bakteria. Biol. Zentralbl. 22:257-262.

23. Winogradsky, S. 1888. Beiträge zur Morphologie und Physiologie der Bakterien. Heft I. Zur Morphologie und Physiologie der Schwefelbakterien. A. Felix, Leipzig. 